\title{
SENTIMENTO DE GRATIDÃO EM CRIANÇAS DE 5 A 12 ANOS ${ }^{1}$
}

\author{
Lia Beatriz de Lucca Freitas \\ Paula Grazziotin Silveira ${ }^{\#}$ \\ Maria Adélia Minghelli Pieta
}

\begin{abstract}
RESUMO. Apresentam-se resultados de um estudo sobre o desenvolvimento do sentimento de gratidão na infância. Os participantes foram 12 crianças, igualmente distribuídas em três grupos etários (5-6, 7-8 e 11-12 anos) e por sexo. Utilizaramse três histórias sobre situações hipotéticas, as quais enfocam diferentes tipos de ação benevolente. Após cada história, realizou-se uma entrevista clínica com a criança. Os resultados sugerem uma diferença entre os grupos etários quanto aos tipos de sentimento positivo atribuídos ao beneficiário da ação. Embora pouco referida pelos participantes, a consideração da mudança do estado sentimental do beneficiário parece contribuir para a compreensão da gratidão. Os resultados indicam ainda que existem diferenças significativas entre os três grupos etários quanto ao tipo de relação estabelecido entre a satisfação experienciada pelo beneficiário e o benfeitor. Os dados encontrados, discutidos à luz da literatura, sugerem novas questões de pesquisa.
\end{abstract}

Palavras-chave: Desenvolvimento; sentimentos; gratidão.

\section{THE FEELING OF GRATITUDE IN 5- TO 12-YEAR-OLD CHILDREN}

\begin{abstract}
Results are presented from a study about the development of the feeling of gratitude in childhood. The participants were 12 children, distributed equally across three age groups (5-6, 7-8, and 11-12 years) and by sex. The study used three stories about hypothetical situations, each focusing on a different type of benevolent action. Following each story, a clinical interview was conducted with each child. The results suggest a difference among the age groups in terms of the types of positive feeling attributed to the beneficiary of the action. Although few participants referred explicitly to this, considering the beneficiary's changed feeling state appears to contribute to the understanding of gratitude. The results reveal significant differences among the three age groups in the types of relation established between the satisfaction felt by the beneficiary and the benefactor. These results, discussed in light of the literature, suggest new research questions.
\end{abstract}

Key words: Development; feelings; gratitude.

\section{EL SENTIMIENTO DE GRATITUD EN NIÑOS DE 5 A 12 AÑOS}

\begin{abstract}
RESUMEN. Se presentan los resultados de un estudio sobre el desarrollo del sentimiento de gratitud en la infancia. Los participantes fueron 12 niños, igualmente distribuidos en tres grupos etarios (5-6, 7-8 y 11-12 años) y por sexo. Se utilizaron tres historias sobre situaciones hipotéticas en las cuales se enfocan diferentes tipos de acciones benevolentes. Después de cada historia, se ha hecho una entrevista clínica con cada niño. Los resultados sujeren una diferencia entre los grupos etarios en relación a los tipos de sentimiento positivo atribuidos al beneficiario de la acción. Aunque poco referida por los participantes, la consideración del cambio del estado sentimental del beneficiario parece contribuir a la comprensión de la gratitud. Los resultados indican aun que existen diferencias significativas entre los tres grupos etarios en relación al tipo de relación establecida entre la satisfación experimentada por el beneficiario y por el bienfactor. Los datos encontrados, discutidos a la luz de la literatura, sujeren nuevas cuestiones de investigación.
\end{abstract}

Palabras-clave: Desarrollo; sentimientos; gratitud.

Este artigo consiste em uma versão revisada e ampliada de trabalho apresentado no VI Congresso Brasileiro de Psicologia do Desenvolvimento, Vitória - ES, em 2007.

* Doutora, professora do Instituto de Psicologia, Programa de Pós-Graduação em Psicologia da Universiade Federal do Rio Grande do Sul-UFRGS.

\# Doutoranda do Programa de Pós-Graduação em Psicologia da UFRGS.

II $\quad$ Mestre em Psicologia. 
Neste século, as emoções e os sentimentos têm despertado o interesse dos pesquisadores, especialmente enquanto motivadores do comportamento moral (Gibbs, 2003), todavia a gratidão tem sido menos estudada que outros sentimentos considerados importantes para a moralidade (McCullough, Emmons, Kilpatrick, \& Larson, 2001). Um pequeno número de pesquisas foi realizado sobre o desenvolvimento da gratidão na infância e ainda um menor número sobre as relações entre gratidão, ingratidão e moralidade (Shelton, 2004). Em uma busca no banco de dados PsycInfo, utilizando-se o descritor gratitude, foram encontrados 46 artigos empíricos no período compreendido entre 2000 e 2007. Desses artigos apenas um referia-se a uma pesquisa realizada com crianças. No Brasil, realizou-se a mesma busca nos bancos de dados da Scielo e da Biblioteca Virtual de Saúde em Psicologia (BVS-PSI) e nenhuma referência foi encontrada.

$\mathrm{Na}$ sociedade ocidental contemporânea, as pessoas, em geral, preferem pensar que são autossuficientes, enquanto a gratidão implica a consciência e o reconhecimento da própria vulnerabilidade e dependência. Segundo Solomon (2004), isso poderia ajudar a compreender por que a gratidão tem sido negligenciada, embora ela se encontre "no coração da ética" (p. vi).

A gratidão é valorizada na maioria das culturas; a ingratidão é considerada uma falha moral. Enquanto a gratidão pode criar ou fortalecer vínculos entre os seres humanos, a ingratidão, pelo contrário, pode enfraquecê-los ou até mesmo destruí-los. Vários autores têm apontado o fato de que a gratidão pode contribuir para promover o bem-estar e melhorar a qualidade de vida daqueles que a experienciam (Emmons \& Crumpler, 2000; Emmons \& McCullough, 2003; Frederickson, 2001; Paludo \& Koller, 2006; Seligman \& Csikszentmihalyi, 2000). Adam Smith (1759/2002) já havia considerado a gratidão como um dos principais motivadores da benevolência, portanto, um importante sentimento para manter a estabilidade de uma sociedade fundada na boa vontade. Este tipo de sociedade seria mais atrativa do que aquelas baseadas apenas em relações utilitárias.

Assim sendo, é muito importante descobrir se e como a gratidão se desenvolve ao longo da infância, bem como explicitar quais são as relações entre a gratidão e a esfera moral. Considerando-se que "o estudo da criança nos permite conhecer não apenas as características dos seres humanos de uma determinada idade, como também todo o processo pelo qual se chega a ser adulto" (Delval, 2002, p. 34), acredita-se que estudos sobre a gratidão, conduzidos a partir de uma perspectiva de desenvolvimento moral, possam fornecer dados relevantes para esclarecer as relações entre gratidão, ingratidão e moralidade.

Neste artigo, são apresentados resultados iniciais de um estudo com crianças de 5 a 12 anos, da cidade de Porto Alegre - RS, que buscou investigar o desenvolvimento do sentimento de gratidão ao longo da infância.

\section{O SENTIMENTO DE GRATIDÃO}

O fenômeno da gratidão encontra-se presente em uma ampla variedade de contextos pessoais e sociais. Fala-se não apenas de gratidão entre indivíduos, mas também, por exemplo, de nações gratas. Na literatura sobre o assunto pode-se observar que não existe consenso entre os pesquisadores sobre gratidão e em que ela consiste. Ela tem sido concebida como afeto moral (McCullough et al., 2001), emoção positiva (Fredrickson, 2001), sentimento interindividual (Baumgarten-Tramer, 1938), traço afetivo (McCullough, Emmons, \& Tsang, 2002), virtude moral (La Taille, 2001).

Neste estudo, enfoca-se a gratidão no contexto de serviços prestados e recebidos, sendo considerada como um sentimento interindividual. Leva-se em conta, ainda, o fato de que a gratidão pode ser observada não apenas no comportamento humano, mas também em animais de outras espécies (Bonnie \& de Waal, 2004).

A palavra gratidão, derivada do latim, tem as seguintes origens: gratia, que significa favor, e gratus, que significa agradável. Em português, por exemplo, o adjetivo grato significa tanto agradecido, reconhecido (por exemplo, ela ficou eternamente grata ao médico que lhe salvou a vida), quanto agradável (por exemplo, trata-se de uma grata lembrança). De fato, a satisfação e o reconhecimento parecem ser dois elementos essenciais para se compreender esse sentimento.

A gratidão foi descrita como um sentimento reativo (Baumgarten-Tramer, 1938) ou retributivo (Westermarck, 1928) de um indivíduo a uma ação generosa de outro. A capacidade de sentir satisfação, ou seja, de atribuir um valor positivo a uma ação benevolente tem sido apontada como condição necessária à gratidão (Bonnie \& de Waal, 2004; Klein, 1957/1991; Komter, 2004; Piaget, 1954).

De acordo com La Taille (2006), três aspectos devem ser considerados na generosidade: 1) o altruísmo, visto que, na ação generosa, o beneficiário da ação é o outro; 2) a existência de um sacrifício por 
parte do benfeitor; e 3) o fato de que "dá-se a outrem, não o que lhe cabe de direito, mas sim o que corresponde a uma necessidade singular" (p. 10). Esses três aspectos também merecem ser levados em conta quando se trata de gratidão, entendida como um sentimento reativo de um indivíduo (o beneficiário) a uma ação benevolente de outro (o benfeitor). Para Klein (1957/1991), a satisfação vivenciada decorre do fato de que o indivíduo sente ter recebido "uma dádiva especial que ele deseja guardar” (p. 220). A avaliação das intenções (altruístas ou egoístas) do benfeitor e a ponderação dos custos de sua ação parecem ser também dois componentes importantes da gratidão.

Para Bonnie e de Waal (2004), “embora um apreço aos favores recebidos seja um componente necessário da gratidão, a resposta emocional de sentirse bem por si só não é suficiente" (p. 221-222). Esses autores acreditam que o papel da gratidão nas trocas recíprocas que se observam entre os animais sociais seria promover sentimentos positivos em relação ao benfeitor, o que levaria o beneficiário a buscar retribuir os serviços recebidos. Bonnie e de Waal (2004) propuseram um modelo para explicar os processos psicológicos implicados na gratidão. Quando um indivíduo recebe uma ação generosa de outro, esta ação dá origem a um bom sentimento. $\mathrm{O}$ beneficiário associa esse sentimento ao benfeitor. Além disso, ele reconhece os custos da ação e atribui boas intenções ao benfeitor. Em função disto, o beneficiário torna-se grato não apenas em relação à ação recebida, mas também ao próprio benfeitor. $\mathrm{O}$ beneficiário, então, sente uma dívida em relação ao benfeitor e uma obrigação de retribuir o favor. Finalmente, o beneficiário retorna o favor ao benfeitor e o ciclo continua, porque o benfeitor inicial (agora beneficiário) sente-se bem, etc.

Esse seria o ciclo completo da troca recíproca que conduziria ao sentimento de gratidão ("Ciclo 3"). Não obstante, o ciclo completo nem sempre está presente em uma troca mútua de serviços. Por exemplo, um bom sentimento pode não estar envolvido em uma troca de favores. Muitas vezes a retribuição de um favor é realizada quase que automaticamente ("Ciclo 1"). Outra possibilidade seria a de que um sentimento positivo seja despertado no beneficiário sem que isso leve à avaliação dos custos da ação para o benfeitor ou de suas intenções ("Ciclo 2"). Neste caso, pode-se gerar uma atitude positiva do beneficiário em relação ao benfeitor, mas não haveria uma valorização positiva do próprio benfeitor e, consequentemente, não surgiria o sentimento de obrigação de retribuir o favor.
Esse modelo inspirou-se, em parte, nas ideias de Westermarck (1928), para quem a gratidão seria um sentimento retributivo benevolente, ao contrário do sentimento de vingança, que, embora retributivo, derivaria do ressentimento. Solomon (2004) também vê na gratidão uma espécie de avesso da vingança: enquanto esta última foi caracterizada por Sócrates como a retribuição do mal com o mal, a gratidão seria uma retribuição do bem com o bem. Para Piaget (1965/1977), também o que caracterizaria a gratidão é o fato de que o beneficiário valoriza não apenas a ação do benfeitor, mas o próprio benfeitor. É dessa valorização positiva do próprio benfeitor que decorre o sentimento de uma dívida psicológica do beneficiário e uma obrigação de retribuir-lhe o favor.

Neste estudo, parte-se da ideia de que o modelo de Bonnie e de Waal (2004) poderia não apenas explicar a troca de favores que ocorrem, com diferentes graus de complexidade, em diferentes espécies, mas também para descrever o desenvolvimento do sentimento de gratidão ao longo da infância. Neste caso, os ciclos mais elementares (Ciclos 1 e 2) seriam precursores do ciclo mais complexo (Ciclo 3), o qual explicaria a gratidão propriamente dita.

\section{O DESENVOLVIMENTO DO SENTIMENTO DE GRATIDÃO}

Uma noção elementar de "eu" é um pré-requisito para que sentimentos interindividuais sejam possíveis (Freitas, 1999), portanto, para que um ser humano vivencie algum tipo de reconhecimento pela ação de outro (McAdams \& Bauer, 2004; Piaget, 1954). O bebê evidentemente estabelece trocas afetivas com outras pessoas, principalmente com os seus cuidadores, e quando as revê as reconhece e, por exemplo, lhes sorri, em função do prazer que elas lhe causam; no entanto os afetos desaparecem quase imediatamente após o afastamento da pessoa que os causou. Ora, o reconhecimento, mesmo em suas formas mais elementares, requer a conservação, no tempo, da satisfação vivida. Desta forma, acredita-se que nenhum sentimento de gratidão seja possível, entre seres humanos, antes de aproximadamente dois anos de idade.

Alguns estudos mostram que as crianças são capazes tanto de expressar gratidão quanto de compreender este sentimento. Baumgarten-Tramer (1938) encontrou quatro maneiras de expressar gratidão, com diferentes níveis de complexidade, entre crianças e jovens suíços de 7 a 15 anos. 
Não há consenso entre os pesquisadores sobre a partir de que idade as crianças entendem o sentimento de gratidão: alguns acreditam que essa compreensão não ocorreria antes dos 7 anos de idade (por exemplo, Harris, Olthof, Meerum Terwogt \& Hardman, 1987); outros sugerem que desde os 4 anos as crianças têm alguma ideia sobre gratidão (Russell \& Paris, 1994).

A relação entre o sentimento de gratidão e a intencionalidade da ação do benfeitor também parece desenvolver-se durante a infância. Antes dos 7 anos, as crianças tendem a levar em conta apenas 0 benefício recebido (Lourenço, 2003), e não a intenção do benfeitor (Graham \& Barker, 1990).

Outro aspecto estudado foi o agradecimento por um presente recebido. Gleason e Weintraub (1976) constataram que poucas crianças $(21 \%)$ com menos de 6 anos agradecem a um adulto que lhes deu uma bala, enquanto mais de $80 \%$ das crianças de 10 anos agradecem na mesma situação. Esse dado é bastante curioso quando consideramos que, desde muito cedo, pais e professores incentivam as crianças a agradecer quando recebem um presente ou algum tipo de ajuda. Becker e Smenner (1986) verificaram que crianças pré-escolares (entre $3 \frac{1}{2}$ e $4 \frac{1}{2}$ anos) agradecem mais um adulto que uma outra criança quando recebem um pequeno presente. Esses resultados são sugestivos, embora devam ser considerados com cautela. Por um lado, deve-se ter em mente que um agradecimento nem sempre expressa gratidão; muitas vezes, agradecemos apenas por uma questão de polidez; por outro, segundo La Taille (2001), é através das regras de polidez que a criança pode começar a compreender certas virtudes: "o 'obrigado' aponta para a gratidão" (p. 116).

Esses estudos indicam que é plausível pensar que o sentimento de gratidão se desenvolva ao longo da infância, embora ainda pouco se saiba sobre este desenvolvimento.

\section{MÉTODO}

\section{Participantes}

Neste estudo participaram 12 crianças, igualmente distribuídas em três grupos etários: 5 a 6 anos, 7 a 8 anos e 11 a 12 anos. Em cada nível etário havia igual número de meninas e meninos. As crianças foram selecionadas em uma creche e uma escola, ambas públicas, da cidade de Porto Alegre.

\section{Material e procedimentos}

As crianças foram entrevistadas individualmente em seu próprio ambiente escolar. Nas entrevistas, foram utilizadas três histórias sobre situações hipotéticas vivenciadas por crianças no ambiente escolar ou familiar, nas quais uma personagem (benfeitor) prestou algum tipo de serviço a outra (beneficiário). A ordem de apresentação das histórias foi sistematicamente modificada. Seguem as histórias que foram contadas às crianças.

Era uma vez um menino que se chamava Gabriel $(\text { Gabriela })^{2}$. Em um dia de inverno, chegou um novo menino em sua aula, o qual se chamava João (Joana). Gabriel (Gabriela) estava com frio. Então, João (Joana) emprestou a ele um blusão, que ele tinha em sua mochila mas não estava usando.

Um menino chamado Márcio (Márcia) usava óculos. Na sua escola, os meninos o chamavam de quatro-olhos. Um belo dia, seu amigo Cláudio (Cláudia), que era muito corajoso, disse: "Márcio (Márcia) usa óculos porque é um menino muito inteligente." Nunca mais os meninos de sua escola o chamaram de quatro-olhos.

Valério (Valéria) tinha um cachorrinho chamado Tobi. Um dia Tobi desapareceu de casa e Valério (Valéria) estava muito triste. Mário (Maria), seu vizinho (sua vizinha), que estava fazendo o seu tema de casa, disse: "Não fica triste. Eu te ajudo a procurar o Tobi." Eles passaram a tarde toda procurando por Tobi e, quando já era quase noite, o encontraram. Mário (Maria) não pôde ver TV, pois tinha que terminar o seu tema de casa.

Uma vez que se constatasse que a história havia sido compreendida, realizava-se uma entrevista clínica com a criança, a partir de algumas perguntas básicas. Por exemplo, para a primeira história perguntou-se: 1) Como Gabriel se sentiu? Por quê? 2) Ele sentiu mais alguma coisa? 3) Gabriel sentiu alguma coisa em relação a João? Por quê? Nas demais histórias, seguiuse o mesmo roteiro, mudando-se apenas os nomes das personagens.

As duas primeiras perguntas tinham por objetivo investigar que tipo de sentimento o participante atribuía à personagem beneficiária. A terceira pergunta visou investigar diretamente se o participante atribuía algum sentimento do beneficiário ao benfeitor, caso ainda não o tivesse feito em suas respostas anteriores. As perguntas de justificação buscaram investigar qual a relação estabelecida pela criança entre o sentimento do beneficiário e o benfeitor.

A partir da leitura das entrevistas, construíram-se três categorias de análise: 1) tipos de sentimentos

2 O nome feminino entre parênteses foi empregado para entrevistar os participantes do sexo feminino. 
positivos; 2) mudança de estado sentimental (negativo $\rightarrow$ positivo) e 3) relação entre sentimento positivo e benfeitor. Dois juízes independentes leram todos os protocolos e classificaram as respostas das crianças de acordo com essas categorias. Houve um elevado acordo entre os dois juízes quanto à codificação das respostas. A confiabilidade foi estimada pelo coeficiente Kappa: as medidas obtidas foram acima de 0,82 , exceto em um caso, no qual foi de 0,66. Analisou-se a variação na frequência das respostas, de acordo com as três faixas etárias estabelecidas (5 a 6 anos, 7 a 8 anos e 11 a 12 anos).

\section{RESULTADOS}

\section{Tipos de sentimentos positivos atribuídos ao} beneficiário

A Tabela 1 apresenta a frequência das respostas quanto ao tipo de sentimento positivo atribuído pelos participantes às personagens beneficiárias das três histórias, em função da faixa etária. As respostas das crianças foram classificadas em duas categorias: 1) sentimentos intraindividuais (feliz, alegre, bem, etc.) e 2) sentimentos interindividuais, sendo esta última subdividida em duas subcategorias: "gratidão" (grato, agradecido, reconhecido, etc.) e "outros" (ajudado, apoiado, etc.). Para fins de análise, considerou-se apenas a resposta de maior complexidade ou especificidade dada por cada participante. Por exemplo, se a criança disse que a personagem beneficiária sentiu-se feliz e ajudada, classificamos sua resposta na categoria $2-$ sentimentos interindividuais, subcategoria "outros". Da mesma forma, se ela disse que o beneficiário sentiu-se apoiado e grato, classificamos sua resposta na categoria $2-$ sentimentos interindividuais, subcategoria "gratidão".

Tabela 1. Frequência de Respostas Quanto ao Tipo de Sentimento Positivo Atribuído ao Beneficiário

\begin{tabular}{lcccc}
\hline \multirow{2}{*}{ Faixa etária } & \multirow{2}{*}{ Intraindividual } & \multicolumn{2}{c}{ Interindividual } & \multirow{2}{*}{ Total } \\
\cline { 2 - 4 } & & outro & grato & \\
\hline $5-6$ anos & 12 & 0 & 0 & 12 \\
$7-8$ anos & 4 & 4 & 3 & 11 \\
$11-12$ anos & 3 & 4 & 4 & 11 \\
\hline Total & 19 & 8 & 7 & 34 \\
\hline
\end{tabular}

A análise da Tabela 1 mostra que todos os participantes de 5 a 6 anos atribuíram um sentimento positivo intraindividual à personagem beneficiada pela ação generosa. A gratidão, por outro lado, não foi mencionada. Este sentimento apareceu apenas entre os participantes de 7 anos ou mais, juntamente com outros sentimentos interindividuais, ou seja, gerados nas trocas estabelecidas entre indivíduos. Os três grupos diferem claramente no padrão de suas respostas, $\chi^{2}(4)=14.94, p<.005$. Os dois últimos grupos não diferem significativamente um do outro, todavia, tanto o grupo das crianças de 7 a 8 anos, $\chi^{2}$ $(2)=10.98, p<.005$, quanto o das crianças de 11 a 12 anos, $\chi^{2}(2)=13,38 p<.001$ diferiram significativamente do grupo das crianças préescolares.

\section{Mudança de estado sentimental.}

Neste estudo, os sentimentos negativos não apareceram isoladamente nas respostas dos participantes, mas sempre junto com sentimentos positivos. Em função disso, não se realizou uma análise dos sentimentos negativos análoga àquela dos sentimentos positivos. Não obstante, decidiu-se examinar se os participantes referiam-se a alguma mudança no estado sentimental da personagem beneficiária: inicialmente, em um "estado de privação" ela experimenta, no final da história, algum tipo de sentimento positivo.

Tabela 2. Frequência de Respostas Quanto à Mudança no Estado Sentimental do Beneficiário

\begin{tabular}{lccc}
\hline \multirow{2}{*}{ Faixa etária } & \multicolumn{2}{c}{ Mudança } & \multirow{2}{*}{ Total } \\
\cline { 2 - 3 } & Não & Sim & \\
\hline $5-6$ anos & 11 & 1 & 12 \\
$7-8$ anos & 9 & 3 & 12 \\
11-12 anos & 7 & 5 & 12 \\
Total & 27 & 9 & 36 \\
\hline
\end{tabular}

A Tabela 2 mostra que a mudança no estado sentimental da personagem beneficiária foi pouco referida pelos participantes. Os resultados sugerem que não existe uma diferença significativa entre as crianças das três diferentes faixas etárias, $\chi^{2}(2)=$ $3.56, p>.10$, porém as crianças de 11 a 12 anos tendem a considerar mais a mudança no estado sentimental do beneficiário que as crianças préescolares, $\chi^{2}(1)=3.56, p<.06$.

\section{Relações entre o sentimento positivo do beneficiário e o benfeitor}

Analisou-se, ainda, a relação estabelecida pelos participantes entre o sentimento positivo atribuído à personagem beneficiária e o seu benfeitor (Tabela 3). Três subcategorias foram definidas: 1) sem relação - o participante não estabeleceu qualquer relação entre o sentimento positivo atribuído ao beneficiário e $\mathrm{o}$ benfeitor; 2) com a ação - o participante estabeleceu 
uma relação entre o sentimento positivo atribuído ao beneficiário e a ação do benfeitor; e 3) com o benfeitor - o participante estabeleceu uma relação entre o sentimento positivo atribuído ao beneficiário e o próprio benfeitor. Aqui também se levou em conta apenas a resposta de maior complexidade dada por cada participante ao longo da entrevista. Por exemplo, na terceira história, um menino disse que Valério se sentiu "bem, porque achou" o cachorrinho e, mais adiante, "se sentiu bem, porque alguém ajudou ele". Neste caso, considerou-se que o menino era capaz de estabelecer uma relação entre o sentimento positivo do beneficiário ( sentir-se "bem") e a ação de ajudar do benfeitor. Assim, sua resposta foi classificada na subcategoria "com a ação".

Tabela 3. Frequência de Respostas Quanto às Relações Entre o Sentimento Beneficiário e o Benfeitor

\begin{tabular}{|c|c|c|c|c|}
\hline \multirow{2}{*}{ Faixa etária } & \multicolumn{3}{|c|}{ Tipo de relação } & \multirow{2}{*}{ Tota } \\
\hline & Sem relação & Com a ação & Com o benfeitor & \\
\hline $5-6$ anos & 9 & 3 & 0 & 12 \\
\hline $7-8$ anos & 4 & 6 & 1 & 11 \\
\hline 11-12 anos & 1 & 6 & 4 & 11 \\
\hline Total & 14 & 15 & 5 & 34 \\
\hline
\end{tabular}

O exame da Tabela 3 sugere que se poderia pensar em uma evolução desse aspecto ao longo da infância. As crianças pré-escolares tenderiam a não estabelecer qualquer tipo de relação entre o sentimento positivo do beneficiário e o benfeitor; pelo contrário, as crianças mais velhas (7 a 8 e 11 a 12 anos) estariam mais propensas a estabelecer relações entre o sentimento positivo do beneficiário e o benfeitor (seja apenas com sua ação seja com o próprio benfeitor). A análise dos resultados indicou a existência de uma diferença significativa entre os três grupos, $\chi^{2}(4)=13.19, p<.01$. Observaram-se diferenças significativas entre as crianças pré-escolares e as de 11 a 12 anos, $\chi^{2}(2)=11.38, p<.005$. As crianças de 7 a 8 anos tendem mais que as crianças pré-escolares a estabelecer uma relação entre 0 sentimento do beneficiário e a ação do benfeitor, $\chi^{2}(1)=3.49, p<.07$.

\section{DISCUSSÃO}

Este trabalho apresenta dados de uma pesquisa que busca investigar o desenvolvimento do sentimento de gratidão ao longo da infância. De modo mais específico, procurou-se saber se haveria diferenças no padrão de resposta das crianças de três grupos etários (5-6, 7-8 e 11-12 anos) quanto a três aspectos: 1) tipos de sentimentos atribuídos ao beneficiário; 2) avaliação da mudança de estado sentimental (negativo $\rightarrow$ positivo) do beneficiário e 3) relações estabelecidas entre o sentimento positivo do beneficiário e o benfeitor.

A capacidade de sentir satisfação ou um bom sentimento em função de uma ação benevolente tem sido apontada como condição necessária à gratidão (Bonnie \& de Waal, 2004; Klein, 1957/1991; Komter, 2004; Piaget, 1954). Neste estudo, constatou-se que a maioria dos participantes atribuiu um sentimento positivo à personagem beneficiária.

Os resultados da pesquisa sugerem ainda uma diferença, ao longo da infância, entre os tipos de sentimento positivo que podem ser atribuídos ao beneficiário: as crianças de 5 a 6 anos dizem que a personagem se sentiu feliz, alegre, bem (sentimentos intraindividuais), enquanto a partir dos 7 anos elas referem-se também a sentimentos interindividuais: o beneficiário sentiu-se ajudado, apoiado, agradecido, grato.

Não obstante, dois participantes não atribuíram qualquer sentimento à personagem beneficiária da primeira história. O empréstimo do blusão - explicou um dos participantes - seria uma ação interessada, isto é, o benfeitor visaria a algum tipo de retorno: "Ele [João] fez algo legal pra ele [Gabriel] ser seu amigo”. Este dado leva a pensar que a avaliação das intenções - altruístas ou egoístas - daquele que realiza a ação é um componente essencial da gratidão. Em outras palavras, é apenas quando a ação é vista pelo beneficiário como generosa (La Taille, 2006) que ela é digna de gratidão. Este dado também fala a favor do modelo proposto por Bonnie e de Waal (2004), visto que a atribuição de "boas intenções" ao benfeitor pelo beneficiário, juntamente com a avaliação dos custos da ação generosa, é que levaria o beneficiário a valorizar o próprio benfeitor. Se a avaliação da intencionalidade da ação do benfeitor ocupar, de fato, esse lugar, temse, então, um elemento importante para se compreender o desenvolvimento do sentimento de gratidão na infância, uma vez que resultados de estudos anteriores indicam que, antes dos 7 a 8 anos, as crianças tendem a levar em conta apenas o benefício recebido (Lourenço, 2003), e não a intenção do benfeitor (Graham \& Barker, 1990). Embora este dado esteja longe de ser conclusivo, aponta para um aspecto que necessita ser mais bem investigado.

Outro resultado importante é o fato de que os sentimentos negativos apareceram sempre junto com sentimentos positivos. Os sentimentos negativos, quando surgiram, foram atribuídos à personagem beneficiária antes, e nunca após a ação generosa. Por 
exemplo, uma menina de 6 anos disse: "Valéria se sentiu muito triste. Porque ela gostava muito do cachorro".

Embora pouco referida explicitamente pelos participantes, a consideração da mudança do estado sentimental (negativo $\rightarrow$ positivo) parece também contribuir para a compreensão deste complexo sentimento que é a gratidão. Um bom exemplo disso é a resposta dada à mesma história por uma menina de 8 anos: "A Valéria se sentiu triste, porque antes ela não tinha achado o cachorrinho dela, mas depois ela se sentiu muito feliz que a amiga dela ajudou a procurar e acharam." Considera-se esse resultado relevante, visto que uma ação generosa nem sempre gera um sentimento positivo: há aqueles que são sensíveis à ação benevolente de outra pessoa (McCullough et al., 2001), mas sentem inveja ao invés de gratidão (Klein, 1957/1991). De acordo com Russell e Paris (1994), desde os 4 anos as crianças são capazes de reconhecer a gratidão como essencialmente agradável.

Outro elemento-chave da gratidão parece ser a relação estabelecida entre a satisfação experienciada pelo beneficiário e o benfeitor. $\mathrm{O}$ estabelecimento de tal relação seria condição necessária, embora não suficiente, para o surgimento desse sentimento. De acordo com autores como Bonnie e de Waal (2004) e Piaget (1965/1977), a gratidão implicaria uma valorização positiva do benfeitor, e não apenas de sua ação generosa. É dessa valorização positiva do próprio benfeitor que decorreria o reconhecimento do beneficiário de sua dívida psicológica e a consequente obrigação de retribuir o favor recebido. Adam Smith (1759/2002) já havia chamado a atenção para essa peculiaridade da gratidão. Fala-se de dívida de gratidão, mas não de caridade, de generosidade ou de amizade - observou o filósofo. Os resultados encontrados neste estudo indicam que existem diferenças significativas entre os três grupos etários quanto ao tipo de relação estabelecido entre a satisfação experienciada pelo beneficiário e o benfeitor. As crianças de 7 a 8 anos tenderam mais que as crianças pré-escolares a estabelecer uma relação entre o sentimento do beneficiário e a ação do benfeitor. Um terço das respostas das crianças de 11 a 12 anos consistiu na valorização positiva do próprio benfeitor. Em outras palavras, os resultados sugerem que o "Ciclo 3" de Bonnie e de Waal (2004) caracterizaria, especialmente, as respostas encontradas entre as crianças de 11 a 12 anos. Antes disso, porém, um sentimento positivo seria despertado no beneficiário, sem que este estabeleça uma relação entre esse sentimento e a ação generosa ("Ciclo 2"). Os dados sugerem ainda que, antes de valorizar o próprio benfeitor, haveria um momento intermediário, no qual as crianças valorizariam a ação do benfeitor, ou seja, compreenderiam que a satisfação vivenciada pelo beneficiário decorre, ao menos em parte, da ação generosa do benfeitor. Como nesta pesquisa não se investigou a necessidade ou não de retribuição de um favor, nada se pode dizer sobre o "Ciclo 1".

Devem ser assinaladas algumas limitações deste trabalho. Em primeiro lugar, cabe lembrar que através do método empregado se obtêm as representações que a criança tem e os juízos que ela faz. Sabe-se que existe uma defasagem no tempo entre essas representações e juízos e aquilo que a criança pensa ou sente em uma situação real (Piaget, 1932/1992), porém se acredita, como La Taille (2002), que o que as crianças dizem "talvez esteja defasado em relação ao que, de fato, sentem, mas representa uma fase de desenvolvimento, talvez superada ou em vias de sê-lo, mas existente" (p. 191). Em segundo lugar, embora existam diferenças no padrão de respostas dos três grupos etários, os dados obtidos não são suficientes para estabelecer se existe uma diferença significativa entre as respostas das crianças pré-escolares e as crianças de 7 a 8 anos, bem como entre aquelas dos dois últimos grupos etários. Em terceiro lugar, deve-se referir o tamanho da amostra: o pequeno número de participantes, mais que tirar conclusões, permite refinar questões de pesquisa e indicar direções para novos estudos.

A literatura indica que o sentimento de gratidão se desenvolve ao longo da infância e os resultados encontrados neste estudo corroboram esta idéia, mas é necessário continuar investigando esse desenvolvimento. A educação pode contribuir para formar indivíduos capazes de viver com outros, e desenvolver o sentimento de gratidão é um importante componente para isto. Acredita-se que pesquisas sobre o desenvolvimento da gratidão possam gerar importantes resultados para programas de educação e reeducação e contribuir, desta forma, para a promoção do bem-estar da criança.

\section{REFERÊNCIAS}

Baumgarten-Tramer, F. (1938). "Gratefulness" in children and young people. Journal of Genetic Psychology, 53, 53-66.

Becker, J. A., \& Smenner, P. C. (1986). The spontaneous use of thank you by preschoolers as a function of sex, socioeconomic status, and listener status. Language in Society, 15, 537-546.

Bonnie, K. E., \& de Wall, F. B. M. (2004). Primate social reciprocity and the origin of gratitude. In R. A. Emmons \& M. E. McCullough (Orgs.), The psychology of gratitude (pp. 213-229). New York: Oxford University Press. 
Delval, J. (2002). Introdução à prática do método clínico: descobrindo o pensamento das crianças. (F. Murad, Trad.). Porto Alegre: Artmed (Original publicado em 2001).

Emmons, R. A., \& Crumpler, C. A. (2000). Gratitude as a human strength: Appraising the evidence. Journal of Social and Clinical Psychology, 19(1), 56-69.

Emmons, R. A., \& McCullough, M. E. (2003). Counting blessings versus burdens: An experimental investigation of gratitude and subjective well-being in daily life. Journal of Personality and Social Psychology, 84(2), 377-389.

Fredrickson, B. L. (2001). The role of positive emotions in positive psychology: The broaden-and-build theory of positive emotions. American Psychologist, 56(3), 218-226.

Freitas, L. B. L. (1999). Do mundo amoral à possibilidade de ação moral. Psicologia: Reflexão e Crítica, 12(2), 447-458.

Gibbs, J. C. (2003). Moral development and reality: Beyond the theories of Kohlberg and Hoffman. Thousand Oaks, Ca: Sage.

Gleason, J. B., \& Weintraub, S. (1976). The acquisition of routines in child language. Language in Society, 5, 129-136.

Graham, S., \& Barker, G. P. (1990). The down side of help: An attributional-developmental analysis of helping behavior as a lowability cue. Journal of Educational Psychology, 82(1), 7-14.

Harris, P. L., Olthof, T., Meerum Terwogt, M., \& Hardman, C. E. (1987). Children's knowledge of the situations that provoke emotion. International Journal of Behavioral Development, 10(3), 319-343.

Klein, M. (1991). Inveja e gratidão. (L. P. Chaves, Trad.), Inveja e gratidão e outros trabalhos (1946-1963, pp. 207-267). Rio de Janeiro: Imago (Original publicado em 1957).

Komter, A. E. (2004). Gratitude and gift exchange. In R. A. Emmons, \& M. E. McCullough (Orgs.), The psychology of gratitude (pp. 195-212). New York: Oxford University Press.

La Taille, Y. de (2001). Desenvolvimento moral: A polidez segundo as crianças. Cadernos de Pesquisa, 114, 89-119.

La Taille, Y. de (2002). Vergonha, a ferida moral. Petrópolis: Vozes.

La Taille, Y. de (2006). A importância da generosidade no início da gênese da moralidade na criança. Psicologia: Reflexão e Crítica, 19(1), 9-17.

Lourenço, O. M. (2003). Children's appraisals of anti-social acts: A piagetian perspective. British Journal of Developmental Psychology, 21, 19-31.
McAdams, D. P., \& Bauer, J. J. (2004). Gratitude in modern life: Its manifestations and development. In R. A. Emmons \& M. E. McCullough (Orgs.), The psychology of gratitude (pp. 81-99). New York: Oxford University Press.

McCullough, M. E., Emmons, R. A., \& Tsang, J-A. (2002). The grateful disposition: A conceptual and empirical topography. Journal of Personality and Social Psychology, 82(1), 112-127.

McCullough, M. E., Kilpatrick, S. D., Emmons, R. A., \& Larson, D. B. (2001). Is gratitude a moral affect? Psychological Bulletin, 127(2), 249-266.

Paludo, S., \& Koller, H. L. (2006). Gratidão em contextos de risco: Uma relação possível? Revista Psicodebate 7. Psicología, Cultura y Sociedad, 7, 55-66.

Piaget, J. (1954). Les relations entre l'affectivité et l'intelligence. Paris: Sorbonne.

Piaget, J. (1977). Études sociologiques, $3^{\text {a }}$ edição. Genève: Droz (Original publicado em 1965).

Piaget, J. (1992). Le jugement moral chez l'enfant, $7^{\text {a }}$ edição. Paris: PUF (Original publicado em 1932).

Russell, J. A., \& Paris, F. A. (1994). Do children acquire concepts for complex emotions abruptly? International Journal of Behavioral Development, 17(2), 349-365.

Seligman, M. E. P., \& Csikszentmihalyi, M. (2000). Positive psychology: An introduction. American Psychologist, 55(1), 514.

Shelton, C. M. (2004). Gratitude: Considerations from a moral perspective. In R. A. Emmons \& M. E. McCullough (Orgs.), The psychology of gratitude (pp. 259-281). New York: Oxford University Press.

Smith, A. (2002). Teoria dos sentimentos morais. (L. Luft, Trad.). São Paulo: Martins Fontes (Original publicado em 1759).

Solomon, R. C. (2004). Foreword. In R. A. Emmons \& M. E. McCullough (Orgs.), The psychology of gratitude (pp. v-xi). New York: Oxford University Press.

Westermarck, E. (1928). L'origine et le développement des idées morales. Paris: Payot.

Recebido em 03/12/2007 Aceito em 01/07/2008

Endereço para correspondência :

Lia Beatriz de Lucca Freitas, Universidade Federal do Rio Grande do Sul, Instituto de Psicologia, Rua Ramiro Barcelos, 2600 sala 118, CEP 90035-003, Porto Alegre-RS, Brasil. E-mail: lblf@ufrgs.br 